\title{
Childhood and capability deprivation in Italy: a multidimensional and fuzzy set approach
}

\section{Introduction}

The United Nations Convention on the Rights of the Children (1989) shifted the policy interest to childhood and raised concerns about children's quality of life, the spectrum of their well-being and their behaviour and attitudes within their homes, schools and communities. Moreover, social and cultural perspectives on childhood have liberated research and policy from over reliance on normative developmental accounts (Woodhead 2006). Klasen (2001) and Biggeri (2007) argue that deficiencies in important capabilities during childhood not only reduce the well-being of those suffering from the deficiencies, but may also have broader social implications. Sen (1999) stresses the remarkable deprivation, destitution and oppression observed in one form or another, in rich countries as well as poor ones.

This study aims to gain insights into Italian children's living conditions and deprivation of capabilities and to generate knowledge relevant for creating and enabling the conditions in which children can live flourishing lives. In particular, the contribution of this study to the empirical research should be read in the following way. Our purpose is to broaden the discussion on the crucial topic on children's well-being in Italy, adding some interesting points to the current literature. Indeed, in recent years several studies have used the capability approach to study children living conditions (see for instance, Addabbo et al. 2014, Addabbo and Di Tommaso 2008; Di Tommaso 2007). Nevertheless, with respect to these empirical analyses we consider a more wide set of dimensions beyond the two areas (the capability of senses, imagination, and thought and the capability of play) analysed by these authors. A recent book edited by Biggeri et al. (2011) highlighted the theoretical and practical issues regarding the use of the capability approach in socio-cultural research focusing on children and distinguish between a participatory and nonparticipatory methods on the application of the capability approach to children. Using the latter method implies that children are not directly involved in the identification and measurement of their capabilities.

In the present work we use the capability approach to study Italian children well-being using EUSILC 2009 data. Indeed, in 2009 this survey included a special section on children aged 0-16 that contains information on their play, social interaction opportunities, ect... Though the definition of children capabilities with EU-SILC data is not trivial, we believe that the use of this source of data is an important opportunity. The reasons are multiple: the EU-SILC survey is available for 32 European countries, so that this study could be replicated in other countries than Italy; the child-specific module of EU-SILC 2009 will be repeated in future waves, making it possible to study the evolution of children living conditions in the time; the sample of the EU-SILC survey guarantees the possibility to study children living conditions at sub-national level. Moreover, the EU-SILC is the only major household survey collecting information on households' income and financial situation. This made it possible to include in our analysis both monetary and non monetary aspects of children deprivation.

From a methodological point of view we present an approach based on the fuzzy methodology introduced by Cheli and Lemmi (1995) and then updated by Betti at al. (2006). This methodology, developed for the study of poverty on a multidimensional perspective, is able to preserve the richness of the data available from the EU-SILC survey. The use of fuzzy methodologies under the capability approach has already been explored by some authors in a theoretical and applied perspective 
(Chiappero Martinetti 2006, Addabbo and Facchinetti 2013), but none of these works presented a framework for the study of children living conditions.

To get more insides into children living conditions we combine the fuzzy methodology with the capability approach at a disaggregated level of analysis by three social economic factors (single parent household, household educational level, macro-region ${ }^{1}$ ). International studies (OECD, 2009; UNICEF, 2013) rank Italy at the bottom of children's well-being map, as a result of multiples measures representing different aspects from economic deprivation to subjective well-being. In order to allow the international comparability, these studies focused on national level of a fixed set of independent indicators; however, an aggregated measure at national level may hide territorial specificities and poverty and well-being indicators are interconnected. Besides the well know Italian North/South disparity of financial indicators - confirmed also for households with children - our findings suggest a new duality for Italian children quality of life, given by the multidimensional domains of deprivation internal or external to children's households.

The rest of the paper is organized as follows. In the next section the background underlining the discourse of childhood and the capability approach is discussed. Sections 3 and 4 delineate the research methodology applied and the description of data, items and domains used in the empirical investigation. Section 5 presents the study's findings and section 6 articulates the conclusions.

\section{Childhood and the capability approach}

Although childhood is characterized by a wide diversity across cultural frames, space and time (Facer et al. 2012, p. 172), is an important life stage with a value in itself. Qvortrup (1994) stressed the tendency to regard children as "human becomings" rather than "human beings" where the ultimate goal and end-point of individual development is adulthood. This paper focuses on children as active social actors and as subjects with capabilities \{that\} have crucial role in society (Comim et al. 2011).

The United Nations Convention on the Rights of the Child (UNCRC) has advanced the debate on childhood and altered the view on children from being merely recipients of freedoms and services or beneficiaries of protective measures, to being subjects with rights and participants in the actions impacting on them. The fundamental difference between present discussions about children's rights and those of previous years lies partly in a different picture of the child as deserving personal rights rather than simply protectionist rights (Sünker and Swiderek, 2007). Empirical work in the field of early childhood (Danby and Baker, 1998) has shown that children are competent social agents and have an active social world that is located beyond the audible and visual scrutiny. However, children are not seen naively as actors without any limits to their agency, but as actors with limited and unequal access to action (Bühler-Niederberger and König, 2011).

Children are citizens of contemporary societies and they are also key for the future of society from a dual perspective: as citizens who are relevant for the future of democracies and as constituents of the labour force of tomorrow's economy. The success of an economy and of a society cannot be separated from the lives that members of the society are able to lead (Sen, 1999). Sen argues (1999: 5) that the capabilities that adults enjoy are deeply conditional on their experiences as children. Childhood is

\footnotetext{
${ }^{1}$ The focus lies on the NUTS-1 level according to the Nomenclature of territorial units for statistics, which may
} provide useful insights into living conditions. 
considered a decisive phase in the reproduction of deprivation and social inequality as resource deficiencies during this critical life period which may well have long-term effects on later life. The impact of deprivation on children's life quality has two main facets: their entitlements to a good life in the here and now as young children and the impact inequalities have on the societal development and the potential for children's forthcoming adulthood. Comim et al. (2011) refer to the impact of poverty on children's development by stressing children's disproportional representation among the poor, their suffering from irreversible forms of capability failure in terms of mental, physical, emotional and spiritual development, their vulnerability within the cycle of inter-generational transfer of poverty and the influence of their current well-being for their future.

The intent of this study is to offer insights on Italian's children's well being beyond monetary deprivation. Three socio-economic factors are investigated in relation to children's well being, namely, single parent household, household educational level and macro-regions. Studies underline that the presence of a single parent in the family can seriously increase the risk of poverty for the children (Chen and Corak 2008; Tarki Social Research Institute 2010; Bradshaw et al. 2012; Istat, 2014). Biggeri et al. (2006) acknowledge the influence of the adults (i.e. parents or guardians) on child development and capabilities. Evidence shows the transmission of disadvantage from parents to their children and from childhood to adulthood (Bäckman and Nilsson, 2010). Economic and political analysts recognise a north/south dualism in Italy that has a primary component in the financial and economic status (Daniele et al. 2011, p.7).

For the purposes of this study, it was chosen to engage with the Capability Approach (CA) as an alternative normative framework for the evaluation of human development, well-being and freedom by thinking in terms of human functionings and capabilities. Functionings are "features of the state of an existence of a person" (Hawthorn, 1987) while capabilities represent what people are able to do or to be (Sen 1999 p.18). According to Dean (2009, p. 262), capabilities represent the essential fulcrum between material resources (commodities) and human achievements.

The CA focuses on measuring the well-being of adults whose freedom to choose a life they have reason to value is central to the notion of capabilities (Klasen, 2001). Yet, the question remains: to what extent can the capability approach be brought to bear on the analysis of well-being and deprivation of children? (Klasen, 2001). Biggeri et al (2004) argue that children are subjects of capabilities and that the capability approach can be very useful as a framework of thought and as a normative tool, in analysing children's well-being ${ }^{2}$, poverty and deprivation and in individuating social policies for children human development. It is argued that deficiencies in important capabilities during childhood not only reduce the well-being of those suffering from the deficiencies, but may also have larger societal implications (Klasen, 2001; Biggeri, 2007).

Sen (1987) argues that it is plausible to identify someone as having a low standard of living on the ground that he or she is deprived of decent housing, or adequate food, or basic medical care. However, for Sen the stock of commodity possession is not the right place to stop. Sen stresses that the standard of living must be directly a matter of the life one leads rather than of the resources and means one has to lead a life. According to Sen, the concern should be on the type of life one succeeds in living with the help of commodities, as commodities are means to other ends. So, the focus has to be on what life we lead and what we can or cannot do, can or cannot be.

2 All capabilities together correspond to the overall freedom to lead the life that a person has reason to value (Sen, 1999; Robeyns, 2003, p. 63). 
Nussbaum (2006) developed an open-ended and extendable list ${ }^{3}$ of domains or basic central capabilities for human flourishing as a minimum account of social justice that has proven to be a valuable framework for the operationalization of the approach ${ }^{4}$ and inspired this study.

\section{Methodology}

The data of this study are derived from the European Survey on Income and Living Conditions (EU-SILC). The EU-SILC is an annual survey carried out simultaneously by all EU member states. It is a rich source of statistics on income distribution and aims to provide a complete set of indicators on poverty, social exclusion, pensions and material deprivation. In this paper we use cross-sectional EUSILC 2009 data for Italy. In 2009 the questionnaire of the survey was enlarged by adding a specific module on material deprivation to the standard core survey (European Commission, 2009). This list of target secondary variables relating to material deprivation allows a better understanding of childhood and capability deprivation in Italy.

Based on the nature of the available data, it was decided to conduct a quantitative analysis of the living conditions of children, as a specific subset of a population, using adequate methodological tools, able to preserve the richness of official data and to improve new measures of deprivation. In this study a fuzzy methodology is applied in order to preserve the richness of the CA. In particular, the approach introduced by Cheli and Lemmi (1995) and then updated by Betti et al. (2006) and Lemmi et al. (2010) for studying poverty ${ }^{5}$ is adapted. As Chiappero Martinetti (2006) argues, the fuzzy set theory can be used in order to depict deprivation and well-being indicators in a gradual, rather than a dichotomous, manner.

The methodological approach used in this paper (henceforth Integrated Fuzzy and Relative IFR) was born on the assumption that poverty is a multidimensional phenomenon and a vague predicate that manifests itself in different shades and degrees (fuzzy concept) rather than an attribute that is simply present or absent for individuals in the population, as the traditional poverty approach assumes ${ }^{6}$.

The fuzzy set vision of poverty is particularly adequate for studying children's living conditions and deprivation mainly for two reasons. Firstly, it includes a non fixed value of poverty risk and deprivation, through the introduction of a membership functions (m.f.), i.e. a quantitative specification of individuals/households degrees of poverty and deprivation depending on the other individuals or households included in the analysis. A membership function's value of 0 is always associated with the lowest risk of poverty and deprivation, whereas a value of 1 is associated with the highest risk. Secondly, the multidimensional framework of the IFR approach proposed by Betti et al. (2006) works up on several non-monetary indicators, assumed to be the manifest representation of a restricted number of underlying domains of deprivation, besides a monetary indicator based on the equivalent disposable

\footnotetext{
${ }^{3}$ For Nussbaum's list of basic human capabilities see Nussbaum 2011, pp. 33-34.

${ }^{4}$ Nussbaum's effort to define specific capabilities has been a subject of criticism which has led to the development of alternative potential lists suitable for capabilities' measurement (see Biggeri et al. 2004; Robeyns, 2003; Di Tommaso, 2007; Terzi, 2007; Wolff and De-Shalit, 2007; De Neubourg et al., 2012). Although all these efforts are interesting to review, it cannot be disputed that all lists end up with similar capabilities to the ones Nussbaum has on her's. Considering the minor differentiations, the aforementioned studies constitute a verification of Nussbaum's core capabilities list.

5 This methodology was also implemented in the S.A.M.P.L.E. (Small Area Methods for Poverty and Living Condition Estimates) project, funded by the European Commission (see http://www.sample-project.eu/).

${ }^{6}$ The traditional poverty approach is characterized by a simple dichotomization of the population into poor and non poor defined in relation to some chosen poverty line that represents a certain percentage (generally $50 \%, 60 \%$ or $70 \%$ ) of the mean or the median of the equivalised income distribution.
} 
income. The multidimensional analysis of poverty seems to be one reasonably grounded way to combine the CA and secondary quantitative data, because it includes monetary and non-monetary dimensions going beyond the traditional approach based only on the economic or financial situation? ${ }^{7}$.

As concerns the monetary dimension, the Fuzzy Monetary Indicator (FM) is computed for each individual $i$ by using equation (1):

$$
F M_{i}=\left(1-F_{i}\right)^{\alpha-1}\left(1-L\left(F_{i}\right)\right)=\left(\frac{\sum_{\gamma} w_{\gamma} \mid y_{\gamma}>y_{i}}{\sum_{\gamma} w_{\gamma} \mid y_{\gamma}>y_{1}}\right)^{\alpha-1}\left(\frac{\sum_{\gamma} w_{\gamma} y_{\gamma} \mid y_{\gamma}>y_{i}}{\sum_{\gamma} w_{\gamma} y_{\gamma} \mid y_{\gamma}>y_{1}}\right)
$$

where, $y_{\gamma}$ is the equivalised income, $F_{i}$ is the income distribution function, $w_{\gamma}$ is the sample weight of individual of rank $\gamma(\gamma=1 \ldots n)$ in the ascending income distribution, $L_{i}$ represents the value of the Lorenz curve of income for individual $i$. Therefore the FM indicator takes into account both the share of individuals less poor and the share of the total equivalised income received by all individuals less poor than individual $i$.

The parameter $\alpha$ is chosen so that the mean of the membership function FM is equal to the Head Count of Ratio (HCR), the indicator measuring the number of poor people, i.e. the number of people with income below the poverty line:

$$
E(F M)=H C R
$$

In this manner the scale parameter $\alpha$ allows the comparison of the fuzzy monetary measure with one of the more traditional poverty measures, the HCR. In this study it is assumed the HCR to be equal to the EU standard definition of people at-risk of poverty calculated on the sub-population of household with children.

The computation of the deprivation indicators of the IFR approach involves a long process as reported also in Berti et al. (2014) and Betti et al. (2015). In details, the IFR method follows seven main steps: 1) identification of the relevant survey items; 2 ) transformation of the items into the [0,1] interval, 3) exploratory and/or confirmatory factor analysis to define the latent dimensions; 4) computation of the weights ${ }^{8}$ within each dimension; 5) calculation of the scores for each dimension; 6) calculation of an overall score and the a parameter as for the FM measure; 7) calculation of the deprivation indices.

The identification of the EU-SILC 2009 items referring to children's deprivation relevant under the CA covered the first step of the above process. More details on the choice of the items will be presented in section 4.

Then, in step 2, the items chosen in step 1 were transformed into the $[0,1]$ interval by using the following equation:

\footnotetext{
${ }^{7}$ Qizilbash and Clark (2005) express their concerns on the use of methodology proposed by Cheli and Lemmi (1995). Chiappero Martinetti $(1994 ; 2000)$ has used this approach in the Italian context many times.

${ }^{8}$ The weights $w_{h j}$ are composed of two factors: the dispersion of each elementary item $j$ and its correlation with the other items in the given dimension $h$.
} 


$$
s_{j, i}=1-\frac{1-F\left(c_{j, i}\right)}{1-F(1)}=\frac{F\left(c_{j, i}\right)-F(1)}{1-F(1)} ; j=1,2, \ldots, k ; i=1,2, \ldots, n
$$

Here $c_{j, i}$ is the value of the category of the $j-t h$ item for the $i-t h$ individual and $F\left(c_{j, i}\right)$ is the value of the $j-t h$ item cumulation function for the $i-t h$ individual. When the $j-t h$ item is a dichotomous variable we have $s_{j, i}=0$ for deprivation and 1 otherwise $^{9}$; when the item is instead polychotomous we assign to each unit a value corresponding to the percentage of units that are "better off' than that unit instead of the real value of the category.

In step 3, an exploratory factor analysis was performed in order to confirm the latent structure of the domains previously defined. Then the weights within each domain were computed, covering step 4.

Using the scores and the weights previously computed, the next step (step 5) was the computation of a single, aggregate score for each domain $h$ and individual $i$ as the weighted mean taken over the $j$ items:

$$
s_{h i}=\sum w_{h j} \cdot s_{h j, i} / w_{h j} .
$$

Here $w_{h j}$ is the weight of the $j-t h$ deprivation variable in the $h-t h$ dimension. In step 6 the overall score for the $i-t h$ individual is calculated as the unweighted mean of the individual-specific scores:

$$
S_{i}=\frac{\sum_{h=1}^{m} s_{h i}}{m}
$$

Following the same process used for the FM indicator, a Fuzzy Supplementary (henceforth, FS) measure can then be computed as:

$$
F S_{i}=\left(1-F_{(S), i}\right)^{\alpha-1}\left(1-L_{(S), i}\right)
$$

where the parameter $\alpha$ is determined again equal to the value that allows the overall FS measure rate to be numerically identical to the HCR.

Finally, in step 7 we separately computed the membership function $F S_{h i}$ for each dimension of the deprivation by:

$$
F S_{h i}=\left(1-F_{(S), h i}\right)^{\alpha-1}\left(1-L_{(S), h i}\right)=\left[\frac{\sum_{\gamma=i+1}^{n} w_{h \gamma} \mid s_{h \gamma}>s_{h i}}{\sum_{\gamma=2}^{n} w_{h \gamma} \mid s_{h \gamma}>s_{h 1}}\right]^{\alpha-1}\left[\frac{\sum_{\gamma=i+1}^{n} w_{h \gamma} s_{h \gamma} \mid s_{h \gamma}>s_{h i}}{\sum_{\gamma=2}^{n} w_{h \gamma} s_{h \gamma} \mid s_{h \gamma}>s_{h 1}}\right],
$$

where: $F S_{(S), h i}$ is the distribution function of $s$ evaluated for individual $i$ dimension $h ; 1-F_{(s), h i}$ is for the $i-t h$ individual the proportion of individuals who are less deprived, in the $h-t h$ dimension, than

\footnotetext{
${ }^{9} \mathrm{It}$ is worth noting that $s_{j, i}$ is a score function, thus it is defined in a reversed order with respect to the membership function previously defined.
} 
the individual concerned; $w_{h \gamma}$ is the sample weight of the $i-t h$ individual of rank $\gamma$ in the ascending score distribution in the h-th dimension; $L_{(S), h i}$ is the value of the Lorenz curve of $s$ for individual $\mathrm{i}$ in dimension $\mathrm{h} ; 1-L_{(S), h i}$ is the share of the total lack of deprivation score assigned to all individuals less deprived than the person concerned.

\section{Data, Items and Domains}

The data selected focused on children aged 0-14. Although significant works in the field consider children as those aged 0 to 17 years inclusive, in line with the United Nations Convention on the Rights of Children (1989) the age boundaries 0-14 were chosen for this study. This age group may be subject to higher vulnerability and intergenerational dependence. Moreover, until the age of 14 Italian children attend the same compulsory schools - elementary plus secondary lower school - while in the following years they can differentiate their educational path, e.g. choosing between schools more addressed to University studies or to the labour market. Thus, the age of 14 corresponds to decisive breaking point in Italian children's life. The final data set used in the empirical analysis covers 19,128 individuals from 5,030 households with at least one child aged less than 15 (37.2\% out of the all sampled of households).

EU-SILC 2009 data were selected as adequate to reveal aspects of the multidimensional deprivation of children - and to meet the requisite characteristics (Alkire, 2008). We are aware that the available data can only be considered as potential proxies for capabilities. However, as underlined in the introduction, the use of EU-SILC 2009 data has many advantages: an example is the European comparative study of de Neubourg et al. (2012) that used EU-SILC 2009 data to define 14 domains of deprivation for children living in 32 European countries, including financial items. In addition, other empirical studies, even though based on different databases, defined capabilities using similar observed indicators (see, for instance, Maccagnan 2011 or Addabbo, 2015). In particular, in this study each capability is assumed to be a latent variable that is measured by multiple indicators (see column 2 of Table 1). Such indicators are manifestation of the latent factor, thus a variation in the capability determines a variation in all functioning measures. A selection of the items, from the large set of EUSILC variables, substantively meaningful and useful for the construction of fuzzy monetary (FM) and supplementary indicators (FS) was made. This was a crucial step, since the choice of the capabilities to include in the evaluation was not straightforward. Dimensions were selected based on the restrictions of the existing data. An attempt was made to include a comprehensive list of basic capabilities considering all the available items for children. The items selected were classified into seven components that represent a respective latent capability (see Table 1): the ability to play (PLAY), to be well nourished and clothed (NUTRITION \& CLOTHING), to have an adequate financial budget at household level (FINANCIAL) $^{10}$, to have a social life (AFFILIATION \& SOCIAL LIFE), to live in an adequate housing (SHELTER) and in a good environment (SAFETY) and to be bodily healthy (BODILY HEALTH). They

\footnotetext{
10 Although the inclusion of the financial domain in our analysis may raise some criticism, we believe that to be able to deal with the unexpected dues at household level can give a more comprehensive picture of children's well-being in Italy. Studies on the financial capability are gradually gaining attention (i.e. Johnson and Sherraden, 2007; Zakaria and Sabri, 2013). "It is crucial in modern society that people have the ability to understand, assess and act in their best financial interests" (Johnson and Sherraden, 2007). For this reason, we include also a financial dimension in our analysis. This choice does not affect results for the other capabilities. It means that the findings remain the same if we drop this dimension.
} 
are not referred just to children but they consider a broader complex system in which children spent their life.

The first capability examined was play. Play is an important aspect of the human life for a healthy growth and well-being and it is vital to children's social development. During play, children also increase their social competence and emotional maturity. Play's significance is reinforced since its incorporation as a right for every child at the UN Human Rights Convention on the Rights of the Child (Article 31). Play was measured using items on outdoor leisure equipment, indoor games and books at home suitable for the child's age. Studies challenge the relation between quality of play and play-material deprivation (i.e. Brown, 2012), because the opportunity cost for playing is very high for families with low income (Di Tommaso, 2007). Nevertheless, in prosperous western economies deprivation on playmaterial may affect severely a child's social life and participation especially when it is combined with restrictions to the use of public open spaces (Sutton, 2008).

Nutrition and clothing were measured with very basic indicators such as the ability to be "well" nourished and clothed with new clothes and shoes. Sen refers to Adam Smith's consideration of the functioning of not being "ashamed to appear in public" and his analysis of how commodities such as clothing and shoes are requirements for this achievement. Another component included was a financial one, reflecting the ability of the household to deal with unexpected dues (bills, payments and expenses). Klasen (2000) argues that 'high rates of household debt service may indicate severe financial stress on the household, with obvious impact on present and future well-being' (p.42.).

Affiliation and social life reflects the ability of the child to live with and towards other and to engage in various forms of social interaction. The notion of affiliation is perceived as associating into close connection as a dignified member of a community. Nussbaum (2000, p. 82) distinguishes affiliation as a capability that - together with practical reasoning - organises and suffuses all other capabilities. Wolf and De-Shalit (2007) argue that the lack of social affiliation and relationships may lead to lower life expectancy, while Raynor (2007) found that affiliation is often linked with play and sports. The capability of shelter reflects the quality of adequate housing, which may well intersect with children's health. Klasen (2000) argues that intrinsically, the quality of housing should affect the wellbeing of its occupants directly.

Safety grasps the prevalence or absence of crime and violence, pollution and noise in children's environment. This component is considered of significance as it consists part of the living conditions which may limit the child's well-being irrespectively of how successful the individual is within it.

Bodily health consists of two components focusing on access to medical attention from specialists. Being in good health is one of the most significant dimensions of well-being and the importance of having some kind of guarantee of basic healthcare is primarily concerned with giving people the capability to enhance their state of health (Sen 2009, p. 238).

Di Tommaso (2007) argues on the distinction of the level of generality of the ideal and the empirically implementable list of capabilities. She argues that the ideal data set would contain information about capabilities as well as functionings. But, the measurement of capabilities, requires ad hoc data set where the design of the questionnaire correspond to an enquiry into the "freedom of agency" space (Di Tommaso, 2007, p. 441). A preliminary set of items available was selected, adequate to be used as elementary indicators covering the concept of children's functionings. Some items had to 
be deleted from this preliminary list ${ }^{11}$. Other indicators were found to be not applicable to children of all ages in the range 0-14; e.g. going on school trips is obviously only applicable to children of school age. As argued in de Neubourg and Plavgo (2012), for this problem it is not easy to find a universally acceptable solution. In this paper we choose to count children outside the relevant age group as nondeprived $^{12}$. Table 1 lists the actual 30 deprivation items (both child-specific and household-specific) used in the empirical analysis. All the chosen items are considered at household level ${ }^{13}$. Then they are transformed into the $[0,1]$ interval using equation (3).

The list of deprivation items is arranged into seven domains of children's functionings. The internal reliability (i.e. the degree to which the items in the scale are representative of each latent construct) has been estimated by the Cronbach's alpha index. The reliability of each scale-items ranges from 0.52 to 0.78 (Table 1). Since not all of the alpha coefficients exceeded the 0.70 cut-off recommended by Nunnally and Bernstein (1994), Exploratory Factor Analysis (EFA) was used to give a framework of the domains regardless the theoretical assumptions. The exploratory factor analysis ${ }^{14}$ mostly supports our null hypothesis. Indeed, seven domains were identified reflecting the arrangement presented in Table1 unless two items ${ }^{15}$ that loaded respectively in the third and the first dimension as regards $E_{F A}{ }^{16}$. We proceed to rearrange these two items in the assumed domain in order to create more meaningful groups and according to the experience acquired in this framework.

The fuzzy monetary indicator (FM) derived from EU-SILC is based on disposable household income (the income information refers to the year 2008), which is collected, component by component, at individual level. When averaged over all household members through the use of an appropriate equivalence scale, the household income provides a reliable indication of the monetary well-being of the household. This is also the basis for the calculation of the at-risk-of-poverty rate, which is the main indicator used for measuring poverty at EU level. In particular, the modified-OECD equivalent scale has been applied for comparing the disposable incomes of households of different size and composition. The relative poverty line is fixed at 60 per cent of the median national disposable income. If the equivalent disposable household income is lower than the poverty line, then the household is considered as income poor. The poverty risk indicator is calculated at the household level and the results presented refer only to households with children.

\footnotetext{
${ }^{11}$ Two items (not affording (if want) a personal car and accessibility of public transport) related with the capability of being able to move freely from place to place had to be excluded due to the low Cronbach's alpha value $(<.0 .05)$ (Chronbach 1951).

12 This choice is reasonable to the extent that households without children in particular age classes are not deprived referring to specific items that involve only children in such specific age classes.

13 Measuring items at the household level implies that the respective achievements are, in principle, accessible to all members of the household and recognises the difficulty of inferring differences in access to household resources using household survey data (Klasen, 2000).

${ }^{14}$ To quantify the degree of intercorrelations among the items and the appropriateness of factor analysis, the Measure of Sampling Adequacy (MSA) and partial correlations among items were calculated (Hair et al., 2009). Overall MSA was 0.90 and the MSA of single items ranged between 0.70 and 0.93 , justifying the application of factor analysis. The result was validated by the low values observed in the partial correlations among items that were all much lower than 0.3. Small partial pairwise correlations between the variables after checking all other variables compared to the original correlations confirmed that some underlying structure existed in the set of selected items.

${ }^{15}$ The two items are "Internet connection" and "Invite friends round to play \& eat from time to time".

16 However the final domains, where these two items that have been eliminated, had also the second highest factor loading according to EFA.
} 


\begin{tabular}{|c|c|c|}
\hline CAPABILITIES & INDICATORS/FUNCTIONINGS & $\begin{array}{c}\text { Cronbach's } \\
\text { Alpha }\end{array}$ \\
\hline \multirow{3}{*}{ PLAY } & Outdoor leisure equipment & \multirow{3}{*}{0.78} \\
\hline & Indoor games & \\
\hline & Book at home suitable for their age & \\
\hline \multirow{5}{*}{ NUTRITION \& CLOTHING } & Fresh fruit $\&$ vegetable once a day & \multirow{5}{*}{0.75} \\
\hline & Three meals a day & \\
\hline & $\begin{array}{l}\text { One meal with meat, chicken, or fish (or vegetarian } \\
\text { equivalent) at least once a day }\end{array}$ & \\
\hline & Some new & \\
\hline & Two pairs of properly fitting shoes & \\
\hline \multirow{5}{*}{ FINANCIAL } & Inability to cope with unexpected expenses & \multirow{5}{*}{0.65} \\
\hline & Arrears on mortgage or rent payments & \\
\hline & Arrears on utility bills & \\
\hline & Arrears on hire purchase instalments & \\
\hline & Ability to keep the home adequately warm & \\
\hline \multirow{7}{*}{ AFFILIATION \& SOCIAL LIFE } & Celebrations on special occasions & \multirow{7}{*}{0.75} \\
\hline & Internet connection & \\
\hline & Regular leisure activity & \\
\hline & Invite friends round to play \& eat from time to time & \\
\hline & $\begin{array}{l}\text { Participate in school trips and school events that cost } \\
\text { money }\end{array}$ & \\
\hline & Child holiday away from home at least 1 week for year & \\
\hline & $\begin{array}{l}\text { Outdoor space in the neighbourhood where children can } \\
\text { play safely }\end{array}$ & \\
\hline \multirow{4}{*}{ SHELTER } & The accommodation is too dark & \multirow{4}{*}{0.62} \\
\hline & $\begin{array}{l}\text { The dwelling has an insufficient number of rooms compared } \\
\text { to the number of persons }\end{array}$ & \\
\hline & $\begin{array}{l}\text { The dwelling has leaking roof/damp walls/floors/ } \\
\text { foundations or rot in the window frames }\end{array}$ & \\
\hline & Suitable place to study or do homework & \\
\hline \multirow{4}{*}{ SAFETY } & Crime, Violence, vandalism & \multirow{4}{*}{0.64} \\
\hline & Pollution & \\
\hline & Noise & \\
\hline & Damaged public amenities in the neighbourhood & \\
\hline \multirow[b]{2}{*}{ BODILY HEALTH } & Unmet need for consulting a dentist & \multirow[b]{2}{*}{0.52} \\
\hline & $\begin{array}{l}\text { Unmet need for consulting a GP or specialist excluding } \\
\text { dentists and ophthalmologists }\end{array}$ & \\
\hline
\end{tabular}

Table 1. Capabilities, indicators/functionings and Cronbach'a alpha values resulting from the analysis.

\section{Source: EU-SILC 2009 Data}




\section{Findings}

Table 2 presents the results of the traditional monetary child poverty approach, based on the relative monetary poverty measure of 60 per cent of median equivalent income, the HCR. This poverty measure is currently used in the European Union also for children (Richardson et al., 2008).

Table 2 HCR (percentage of individual living in households with income below the poverty line)

\begin{tabular}{|c|c|c|c|c|c|c|c|c|c|}
\hline \multirow{3}{*}{$\begin{array}{l}\text { Households } \\
\text { with children }\end{array}$} & \multirow{3}{*}{$\begin{array}{c}\text { All } \\
\text { households }\end{array}$} & \multicolumn{8}{|c|}{$\begin{array}{l}\text { Households Characteristics } \\
\text { (only households with children) }\end{array}$} \\
\hline & & \multicolumn{3}{|c|}{ Macro Regions } & \multicolumn{2}{|c|}{ Single parent } & \multicolumn{3}{|c|}{ Educational level } \\
\hline & & North & Centre & South & Yes & No & Low & Medium & High \\
\hline $24 \%$ & $18 \%$ & $11 \%$ & $16 \%$ & $41 \%$ & $31 \%$ & $23 \%$ & $36 \%$ & $17 \%$ & $7 \%$ \\
\hline
\end{tabular}

Source: Our elaboration from EU-SILC 2009 Data

The traditional view of poverty (HCR) depicts, as expected, a country where the risk of poverty among children is much higher than among the whole population ( $24 \%$ vs $18 \%$ ). Although this national trend characterises several Member States, the estimated six percentage points gap in Italy is higher than the European average, equal to approximately three percentage points (European Commission, 2010). Moreover, the risk of poverty among children varies considerably across Italian macro-regions. The disparity between Northern and Southern regions is conspicuous, as the HCR ranges from $11 \%$ to $41 \%$. Central regions play frequently a "mediator effect" between two very different economies: the north where an attitude towards entrepreneurship has found a fertile ground, while in the south it did not happened. The gap between single parent households (with HCR equal to $31 \%$ ) and other household compositions (HCR 23\%) is also evident.

Moreover, the differences in the HCR observed classifying the households according to three alternative educational levels attained by the reference person in the household ${ }^{17}$ were investigated. Education is a basic capability that affects the development and expansion of other capabilities. Household educational level can be used as proxy of the household social class. The study showed that the risk of poverty is very high for children living in households characterised by low educational level (HCR 36\%). In contrast, high household educational levels guard their children from poverty (HCR 7\%).

Table 3 and Figures 1, 2 and 3 report the fuzzy and multidimensional analysis. The "spider graph" displays children's deprivation per macro-region (i.e. Northern, Central and Southern), in single and non-single parent households and in households classified by the reference person's educational level attained. In particular, the graph reports the values assumed by all the FM and the FS indicators calculated with equations (1) and (7). A "perfectly" distributed set of indicators is depicted when the "target populations" lines fully overlap.

Figure 1 illustrates the fuzzy and multidimensional poverty measures by macro-regions. Each region offers a unique synthesis of social, cultural and economic characteristics at various scales. The fuzzy and multidimensional approach allows a better understanding of children's capability deprivation, covering monetary and non monetary aspects.

\footnotetext{
${ }^{17}$ Families are classified based on the major income earner (the person with the highest income in the household). The household educational level has been defined through the International Standard Classification of Education (ISCED). Individuals whose attained educational level is lower than the ISCED level 3 are classified as low-educated while individuals whose ISCED level is greater than 3 are classified as high-educated.
} 
The FM indicator, as expected, reflects the trend of the traditional poverty measure described above. Further, it allows to overcome the strict division between poor and non poor, preserving the richness of data information. Under the fuzzy approach the degree of monetary poverty is higher for children in Southern regions (0.367) than in Northern regions (0.141), whereas it has an average value (0.186) in the Centre: that is, FM is almost three times in the Southern regions respect to the Northern ones. Moreover, the high score of this indicator across macro-regions in relation to the values of the other domains confirms that income poverty remains the main factor in childhood deprivation.

Nevertheless children are also deprived with respect to non-monetary domains with different degree of severity. At national level (see the first column of Table 3 ) the bodily health domain has the lowest value (0.043): this means, as in Klasen (2000) study, that deprivation in this domain compared to the other dimensions is negligible. It should be noted that "bodily health" focuses on the access to health care and in particular on the need for a specialist doctor, which implies a previous identification of the need, which is not measured here. For play and nutrition \& clothing domains similar results (both 0.068 ) are obtained. Italian children basic needs are satisfied in terms of food and clothing, and they are not deprived from medical and specialist care. They have also a good equipment of leisure activities and games. Surely, these are not direct measures of how - and if - children use their equipment, but these results show that they have the possibility to do it. In contrast, the safety and social \& affiliation domains obtained the highest values, 0.194 and 0.170 , respectively. It means that these dimensions have a larger impact respect to others included in the analysis on children deprivation. Italian children appear more vulnerable respect to life outside the family. It could be represented as "duality": internal to own family and external to it. Aspects which are more related to familial or internal dimensions are more amenable to alternative non-monetary resourcing, such as food and health, while such solutions are less available for aspects of social life and the quality of environment.

It is worth noting that, indicators included in social \& affiliation domains strongly imply expenditures for family, i.e. school trips or sport activities. If we wanted to observe the trend of these kind of expenditures and also explain the relationship between the investments in social life and the pick of the economic and financial crisis of 2009 , we have to extend the analysis at a longitudinal level. In our data framework, it is possible for the moment just to suppose a cause-effect relationship between the economic difficulties of the families and the low level of expenditures devoted to social activities.

The negative evaluation of quality of environment signals the lack of safety threatened by crime, violence, vandalism, pollution, noise or by damaged public amenities in the neighbourhood. Regional disparities according to the domain safety are also observed with the South of Italy urging for immediate measures to address the severity of the situation. Lastly for shelter and financial domains, median results were obtained, that is the third and fourth highest values respectively.

It is interesting to observe the ranking of the non-monetary domains per three macro regions. The analysis confirms that a north/south dualism in Italy has a primary component in the financial and economic status also for households with children. The fuzzy monetary domain plays a crucial role for determining children's deprivation in central and southern regions, while in northern regions shelter and safety conditions seem to be more important than monetary condition. The lowest value is observed on the bodily health domain in the three macro-regions, while the lowest level of children's deprivation in this domain appears to be in central regions. Among the macro regions, the value of the capability of play is more than double in the South in comparison with the other two macro-regions: 0.104 versus 0.047 in the North and 0.046 in the Centre. The same gap is observed also for other dimensions, 
confirming a better evaluation for "inside" dimensions and a worst one for environment quality and community life.

These findings suggest a sort of "dual duality" in Italian children quality of life: near to the traditional north/south, the new internal/external life comes from the fuzzy approach. As the first dualism has been studied for a long time, addressing the new one could be the way also to reduce the distance between the north and south of Italy on children's quality of life.

Table 3 Fuzzy and multidimensional poverty measures (only households with children)

\begin{tabular}{|c|c|c|c|c|c|c|c|c|c|}
\hline \multirow[b]{3}{*}{ Description } & \multirow[b]{3}{*}{ Italy } & \multicolumn{8}{|c|}{ Households Characteristics } \\
\hline & & \multicolumn{3}{|c|}{ Macro Regions } & \multicolumn{2}{|c|}{ Single parent } & \multicolumn{3}{|c|}{ Educational level } \\
\hline & & North & Centre & South & Yes & No & Low & Medium & High \\
\hline FUZZY MONETARY & 0.236 & 0.141 & 0.186 & 0.367 & 0.30 & 0.23 & 0.34 & 0.18 & 0.09 \\
\hline PLAY & 0.068 & 0.047 & 0.046 & 0.104 & 0.10 & 0.07 & 0.11 & 0.04 & 0.01 \\
\hline NUTRITION \& CLOTHING & 0.068 & 0.051 & 0.044 & 0.099 & 0.07 & 0.07 & 0.11 & 0.04 & 0.02 \\
\hline FINANCIAL & 0.160 & 0.120 & 0.154 & 0.210 & 0.22 & 0.16 & 0.24 & 0.11 & 0.08 \\
\hline AFFILIATION \& SOCIAL PARTICIPATION & 0.170 & 0.111 & 0.126 & 0.261 & 0.21 & 0.17 & 0.25 & 0.12 & 0.08 \\
\hline SHELTHER & 0.169 & 0.143 & 0.172 & 0.198 & 0.19 & 0.17 & 0.22 & 0.14 & 0.12 \\
\hline SAFETY & 0.194 & 0.170 & 0.180 & 0.230 & 0.22 & 0.19 & 0.19 & 0.19 & 0.21 \\
\hline BODILY HEALTH & 0.043 & 0.039 & 0.026 & 0.055 & 0.08 & 0.04 & 0.07 & 0.02 & 0.02 \\
\hline
\end{tabular}

We investigated the influence of the household-types (single and non-single parent) to the economic situation of the family and of children's capabilities (see Table 3 and Figure 2). Single parent households (not widowed) are the $9.9 \%$ of total number of Italian households according to the 2011 Population and Housing Census ${ }^{18}$. This means more than 1.5 million of households and 3.7 millions of individuals and their quota has growing during time (+47\% since 2006-2007). A large part of them are the effects of increasing separation and divorces and they are more present in the Central and Northern part of country, where these behaviours are more common. Single parent households are almost exclusively composed by woman and children (83.7\%) and they are more vulnerable than the other type of households (Istat, 2014): the absolute poverty increased from 5\% to $8 \%$ in $2011-2012$ and from $5.8 \%$ to $9.1 \%$ in the case of single parent households. The analysis confirms the vulnerability of single parent household: the values obtained for the FM and for the FS indicators are all higher for households with a single parent, with the only exception of the nutrition and clothing domain, where the results are equal. These last domains are part of care work, which remains a task mainly burdening women both on single- and in two-parent families (Istat, 2012). Women and children mainly compose single parent households and this gender composition may imply a low disadvantage on good meals and adequate clothing in such households.

The bodily health dimension is the one where the highest gap between the two groups of households is observed: in this case the value of households with a single parent is the double with respect to the value obtained for all the other households. As said before, the access to a specialist involves economic expenditure and the single parent are financial weaker. This could be the reason of the huge gap between the two household types.

18 Data from dati.istat.it 
Literature (Istat, 2014; Bradshaw et al., 2012; Krueger \& Lindhal 2001) and empirical evidence show (Tarki Social Research Institute, 2010) that the level of education of the household members influences the child's survival and development chances as well as their risk of poverty. The consideration of three separated groups of households - those where the head of the household has low, medium or high educational level - led to interesting results (see table 3 and Figure 3 ). In the first two groups, the analysis shows that safety domain is the most relevant, implying a central role for children's capabilities enhancement. Further, the lowest gap between low and high-educated families for this dimension is observed. Yet, the analysis conducted by educational status enhances the distance for the play dimension, which is eleven times higher for households with low education level with respect to households with high one. For nutrition and clothing, bodily health, affiliation \& social participation and financial the gap is very pronounced - the values of the low educated households are at least three times higher in comparison with high educated ones.

It is worth noting that by considering the last two disaggregation criteria, the ranking of domains remain the same, with minor changes. This confirms the hypothesis of internal/external factors concurring to determine children's well-being following the CA approach.

Figure 1. Fuzzy and multidimensional poverty measures by macro-regions. We have to change SAFETY in the figure!

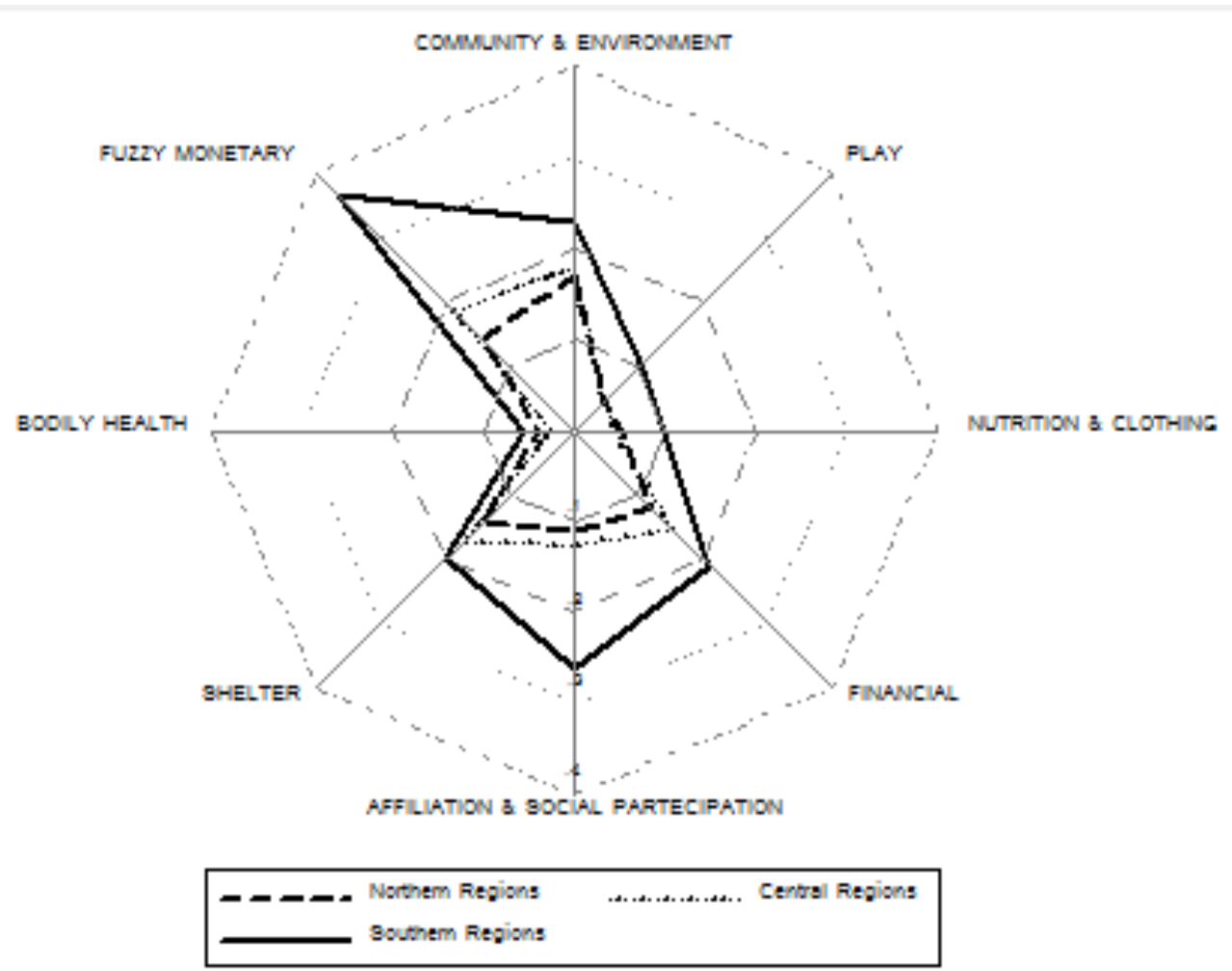


Figure 2. Fuzzy and multidimensional poverty measures by household composition. We have to change SAFETY in the figure!

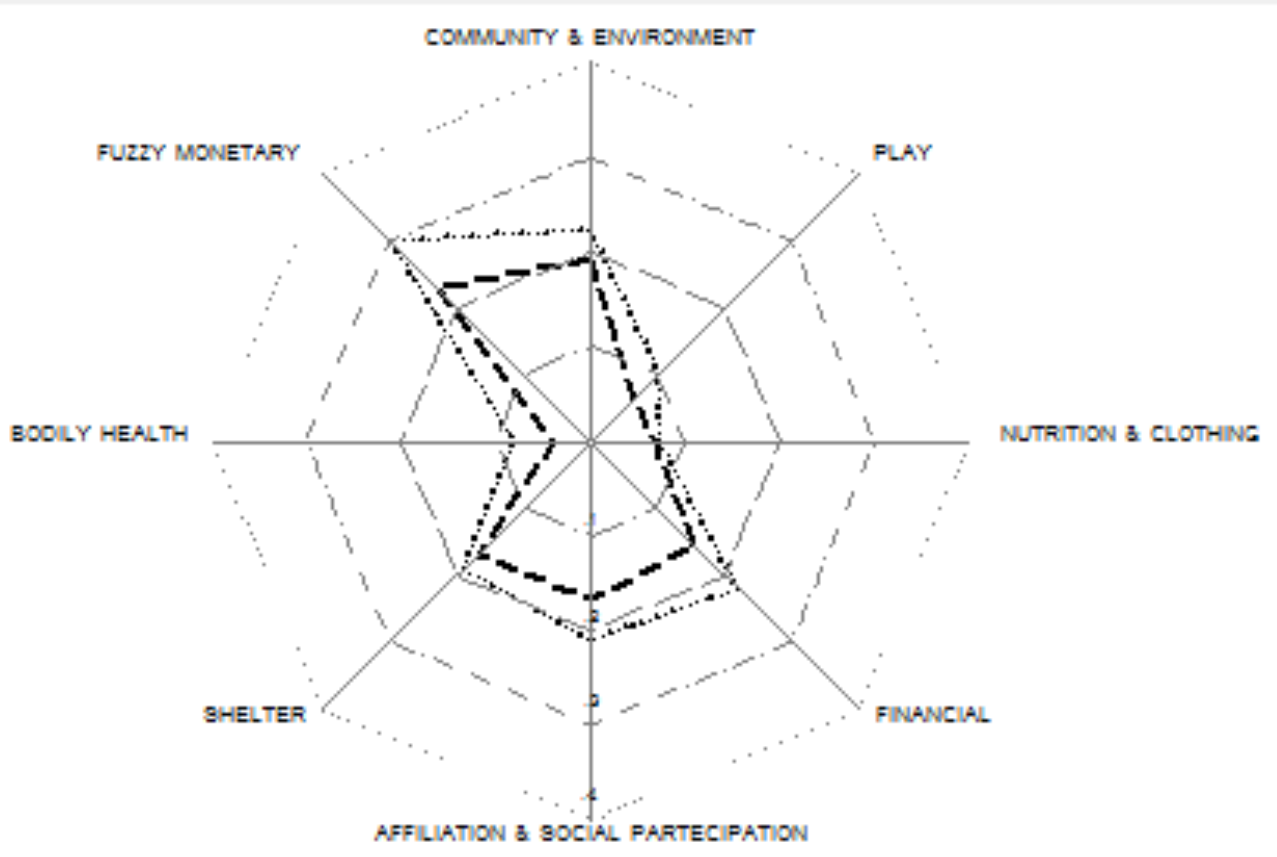

Figure 3. Fuzzy and multidimensional poverty measures by educational level. We have to change SAFETY in the figure! 


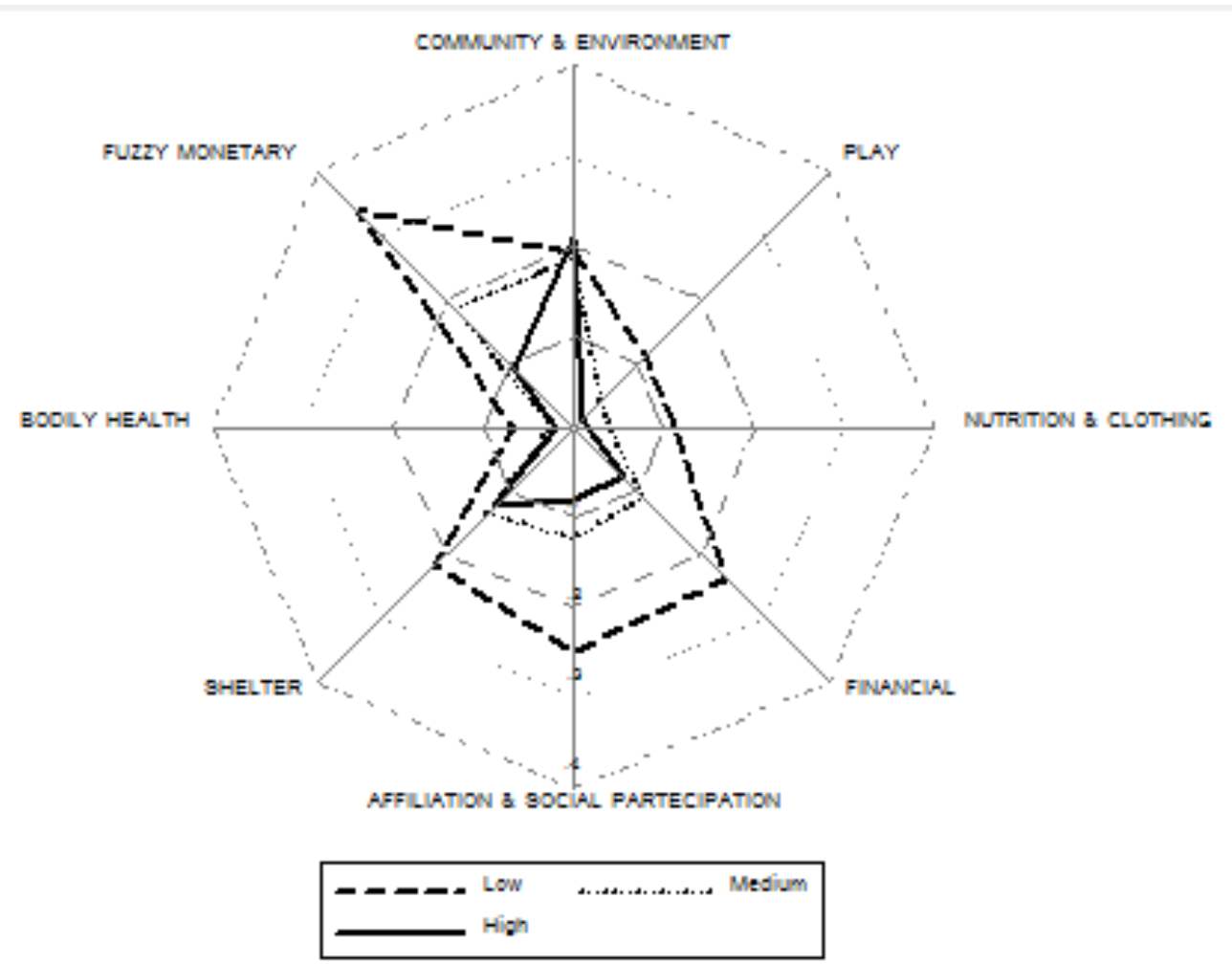

\section{Concluding remarks}

This study shed light on Italian children's living-conditions and their capabilities deprivation with the use of the 2009 EU-SILC wave data. Looking beyond children's monetary poverty to children's basic capabilities we offered a comprehensive picture of children's deprivation also considering the disaggregation of the analysis according some important social economic factors. From a methodological point of view, the use of the fuzzy methodological perspective proposed by Betti et al. (2006) allowed the preservation of the richness of the capability approach.

Evidence showed that children are threatened by the risk of poverty significantly higher in comparison with the country's population as a whole and that the percentage of threat exceeds considerably the European average. Moreover, the unequal geography of opportunity is observed on a regional level as the risk of poverty among children varies considerably across macro-regions, indicating great disparities between Northern and Southern regions while the central regions are lying somewhere in between. The high score assumed by this indicator across macro-regions with respect to the other domains verifies that income poverty is still the main factor in childhood deprivation. The extent of regional disparities is rather wide especially for a developed country such as Italy. The gap between single parent households and other household compositions is also evident, as well the differences observed in the poverty risk by classifying the households according to the educational level of the household reference person.

However, monetary deprivation is only an aspect of children's well-being. Children's deprivation with respect to other non-monetary domains has been investigated. Findings show that, at national level, the bodily health domain has the lowest value and subsequently the best performance in the well-being of household with children. It has to be noted that in this scheme bodily health represents the need for a 
specialist, which implies a previous identification of the need. Similar results were observed for play and nutrition and clothing domains. Despite financial restrains, Italian children are not deprived in terms of adequate medical and specialist care as well as it terms of food and clothing. Although they have the means to play, affiliation and social participation is a domain of deprivation. In addition to affiliation and social participation the domain of safety also performs worse than the other capabilities. Child deprivation often links to social exclusion in the lived experiences of children both at school and in the wider community especially in periods such as the recent global economic and financial crisis that has fuelled and aggravated social inequality (UNICEF, 2014). Households, communities and political arenas respond to poverty impacts on the basic standards for living (shelter, nutrition, health) but the impact on participation is not on political agendas and cannot be offset at household or community levels. This has serious implications for quality of life and future modes of citizenship. Children need living in an environment free of pollution and noise, not having experience of crime and violence. All of these aspects could be object of local policies, aiming to improve the quality of life of children and communities.

Given the results of fuzzy approach, it is possible to introduced a new interpretation of the factors impacting on Italian children deprivation, in addition to the usual territorial disparities (North vs South). A duality of Italian life emerged: internal to own family and external. Aspects which are more properly related to a familial or internal dimensions are more amenable to alternative non-monetary resourcing, such as food and health, while such solutions are less available for aspects of social life and the quality of environment. This consideration implies to broad the analysis including also a sociological approach both to read the results and to operationalize them. Indeed, monetary investments are not sufficient to increase the social participation, overall when children are involved. Family choices regarding allocation of children time and activities implies a larger set of considerations: economic status of household, parents' expectations, and their available time; the behaviours of peers and others. Evidences of this study confirm that there is a strong relationship between the factors beyond the children well-being and that the capabilities are stretched out on a cultural and social carpet which is needed to be included in the analysis.

The observed disparities - territorial and social - properly interpreted might be the base for planning policies directed at improving children's living conditions. Enhancing the quality of children's life, influenced by education, health care, security and prevention of trauma can be crucially significant as a part of development. The quality of childhood is important not only for what happens in childhood but also for future life. Therefore, investment in features of childhood opportunities can enhance future capabilities in quite different ways, because a securely preparatory childhood can directly make adult lives richer and less problematic by augmenting the skill in living a good life.

In future developments of the present study we aim at extending the analysis to other European countries for which EU-SILC 2009 data are available. We also aim at repeating the analysis using EUSILC 2014 data, since the ad-hoc module will again include child specific items. This new analysis will allow us to get some insides on the effect of the financial crisis on European children.

\section{References:}


Addabbo T., and Di Tommaso M.L.: Children capabilities and family characteristics in Italy. Paper Prepared for the 30th General Conference of The International Association for Research in Income and Wealth, Portoroz, Slovenia, August 24-30 (2008)

Addabbo T., and Facchinetti G.: The fuzzy logic and the capability approach. CAPPaper n. 106 (2013)

Alkire, S.: Choosing Dimensions: The Capability Approach and Multidimensional Poverty. MPRA Paper No. 8862 (2008).

Bäckman, O., Nilsson, A.: Pathways to social exclusion - a life-course study. European Sociological Review, 27(1), 107-123 (2010)

Berti, F., D'Agostino, A., Lemmi A., Neri L.: Poverty and deprivation of immigrants vs. natives in Italy. International Journal of Social Economics, 41(8), 630 - 649 (2014)

Betti G. Gagliardi F., Lemmi A. and Verma V. (2015), Comparative Measures of Multidimensional Deprivation in the European Union, Empirical Economics, DOI 10.1007/s00181-014-0904-9

Betti, G., Cheli, B., Lemmi, A. and Verma, V.: Multidimensional and Longitudinal Poverty: an Integrated Fuzzy Approach. In: Lemmi, A. and Betti, G. (ed.), Fuzzy Set Approach to Multidimensional Poverty Measurement, Springer, New York, 111-137 (2006).

Bühler-Niederberger, D., König, A.: Childhood as a resource and laboratory for the self-project. Childhood, 18(2), 180-195 (2011)

Biggeri M.,Ballet, J. and Comim F. (eds.): Children and the Capability Approach studies in childhood and youth. Palgrave Macmillan (2011)

Biggeri, M., Libanora, R., Mariani, S., \& Menchini, L.: Children establishing their capabilities: Preliminary results of the survey during the first children's world congress on child labour. Paper presented at the 4th International Conference on the Capability Approach, "Enhancing Human Security, University of Pavia, Italy, (2004). Retrieved from http://cfs.unipv.it/ca2004/papers/biggeri.pdf

Biggeri, M., Libanora, R., Mariani, S., Menchini, L.: Children Conceptualizing their Capabilities: Results of a Survey Conducted during the First Children's World Congress on Child Labour. Journal of Human Development and Capabilities, Taylor \& Francis Journals, 7(1), 59-83 (2006)

Biggeri, M.: Children's valued capabilities. In: Amartya Sen's capability approach and social justice in education, Melanie Walker \& Elaine Unterhalter (Eds.). Palgrave McMillan: New York (2007)

Bradshaw, J., Chzhen, Y., de Neubourg, C., Main, G., Martorano, B. and Menchini, L.: Relative income poverty among children in rich countries. Innocenti Working Paper 2012-01 (2012)

Brown, F.: The play behaviours of Roma children in Transylvania. International Journal of Play, 1(1), 64-74 (2012)

Cheli, B. and Lemmi, A.: A Totally Fuzzy and Relative Approach to the Multidimensional Analysis of Poverty. Economic Notes, 24(1), 115-134 (1995)

Chen W-H., Corak M.: Child poverty and changes in child poverty', Demography, 45(3), 537-553 (2008)

Chiappero Martinetti, E.: A New Approach to Evaluation of Well-being and Poverty by Fuzzy set Theory. Giornale Degli Economisti e Annali di Economia (1994)

Chiappero Martinetti, E.: A multi-dimensional assessment of well-being based on Sen's functioning theory. Revista Internazionale di Scienza Soziali CVIII (2), 207-239 (2000)

Chiappero-Martinetti, E.: Capability approach and fuzzy set theory: description, aggregation and inference. In: Fuzzy set approach to multidimensional poverty measurement, Lemmi, A., Betti, G (eds.), Springer (2006)

Comim, F., Ballet, J., Biggeri, M., lervese, V.: Introduction-theoretical foundations and the book's roadmap. In: Children and the Capability Approach studies in childhood and youth, Mario Biggeri, Jérôme Ballet, Flavio Comim (eds.). Palgrave Macmillan (2011)

Cronbach L.J.: Coefficient alpha and the internal structure of tests. Psychometrika 16, 297-333 (1951)

Danby, S., \& Baker, C.: What is the problem?" Restoring social order in the preschool classroom. In I. Hutchby \& J. Moran-Ellis (Eds.), Children and social competence: Arenas of action, 157-186, London, England: Falmer Press (1998)

Daniele V. and Malanima P.: II divario Nord-Sud in Italia 1861-2011. Soveria Mannelli, Rubbettino (2011)

Dean, H.: Critiquing capabilities: the distractions of a beguiling concept. Critical Social Policy, 29(1), 261-278 (2009)

Di Tommaso M. L.: Children capabilities: A structural equation model for India, The Journal of Socio-Economics 36 (2007) 436-450

European Commission: EU-SILC Module on material deprivation. (2009)

European Commission: Child poverty and child well-being in the European Union. DG Employment, Social Affairs and Equal Opportunities, Unit E.2 Volume I: Main report (2010)

Facer, K., Holmes, R., Lee, N.: Editorial. Global Studies of Childhood, 2(3), $170 \quad-175$ (2012).http://dx.doi.org/10.2304/gsch.2012.2.3.170

Istat: Uso del tempo e ruoli di genere. Tra lavoro e famiglia nel ciclo di vita. Istituto Nazionale di Statistica, Roma 
(2012)

Istat: Rapporto annuale 2014: La situazione del Paese. Istituto Nazionale di Statistica, Roma (2014)

Hawthorn, G. (ed.): The Standard of Living. Cambridge University Press: Cambridge (1987)

Johson, E., Sherradon, M.S.: From financial literacy to financial capability among youth. Journal of Sociology \& Social Welfare, September 2007, Volume XXXIV, Number 3, (2007), 119-145

Klasen, S.: Measuring poverty and deprivation in South Africa. Review of Income and Wealth, 46(1), 33-58 (2000)

Klasen, S.: Social exclusion, children and education: Implications of a rights-based approach. European Societies 3(4), 413-445 (2001)

Krueger A.B., Lindahl M.: Education for growth: why and for whom?. Journal of Economic Literature, Vol. XXXIX, 1101-1136 (2001)

Lemmi, A., Verma, V., Betti, G., Neri, L., Gagliardi, F., Tarditi, G., Ferretti, C., Kordos, J., Panek, T., SzukiełojćBieńkuńska, A., Szulc, A., Zięba, A.: Multidimensional and fuzzy indicators developments. Project Small Area Methods for Poverty and Living Conditions Estimates. No. EU-FP7-SSH-2007-1 (2010)

Maccagnan, Anna. 2011. "Measuring the Interaction Between Parents and Children in Italian Families: A Structural Equation Approach."Working Paper 645, Department of Political Economics, Universitá di Modena e Reggio Emilia, Modena, Italy.

Neubourg de, C., Bradshaw, J., Chzhen, Y., Main, G., Martorano, B. and Menchini, L.: Child deprivation, multidimensional poverty and monetary poverty in Europe. Innocenti Working Paper 2012-02 (2012)

Neubourg de, C. and Plavgo i.:. Lost in Dimensions, Choices in Multidimensional Poverty Analysis Critically Reviewed. UNICEF, Innocenti Working Paper, (2012).

Nunnally, J.C. and Bernstein, I.H.: Psychometric theory (3rd ed.). New York: McGraw-Hill (1994)

Nussbaum, M. (2000), Women and Human Development: The Capabilities Approach, Cambridge: Cambridge University Press

Nussbaum, M.: Education and democratic citizenship: Capabilities and quality education. Journal of Human Development, 7(3), 385-395 (2006)

Nussbaum, M.: Creating capabilities: the human development approach, Harvard University Press (2011)

OECD: Doing better for children. OECD Publishing (2009)

Qizilbash, M. \& Clark, D.A.: The capability approach and fuzzy poverty measures: an application to the South African Context. Social Indicators Research , 74, 103-139 (2005)

Qvortrup, J. (1994) 'Childhood Matters: An Introduction', in J. Qvortrup, M. Bardy, G. Sgritta and H. Wintersberger (eds) Childhood Matters. Social Theory, Practice and Politics, pp. 1-24. Aldershot: Avebury.

Robeyns, I.: The Capability Approach: An interdisciplinary introduction. Paper presented to the Training Course preceding the 3rd International Conference on the Capability Approach, Pavia, Italy (2003) Retrieved from http://www.soc.spbu.ru/img/up/files/File/1.8\%20Robeyns\%20The\%20Capability\%20Approach.\%20An\%20Interdiscipli nary\%20Introduction.pdf

Raynor, J.: Education and capabilities in Bangladesh. In: Amartya Sen's capability approach and social justice in education, Melanie Walker \& Elaine Unterhalter (Eds.). Palgrave McMillan: New York (2007)

Richardson, D., Hoelscher, P. and Bradshaw, J.: Child well-being in Central and Eastern European countries (CEE) and the Commonwealth of Independent States (CIS). Child Indicators Research, 1(3), 211-250, (2008)

Sen, A. K.. The Standard of Living: The Tanner Lectures, Cambridge: Cambridge University Press (1987)

Sen, A. K.: Breaking the poverty cycle - investing in early childhood. Keynote Address, Inter-American Development Bank, Sustainable Development Department, Social Department Division. Paris, (March 14, 1999) Retrievied from: http://www.unicef.org/lac/spbarbados/Implementation/ECD/BreakingPovertyCycle_ECD_1999.pdf

Sen, A.: The idea of Justice. The Belknap Press of Harvard University Press Cambridge, Massachusetts (2009)

Sutton, L.: The state of play: disadvantage, play and children's well-being. Social Policy and Society, 7(4), 537-549 (2008)

Sünker, H., \& Swiderek, T.: Politics of childhood, democracy and communal life: Conditions of political socialization and education. Policy Futures in Education, 5(3), 303-314 (2007)

Tarki Social Research Institute: Child poverty and child well-being in the European Union. Report for the European Commission (2010)

Terzi, L.: The capability to be educated. In M. Walker \& E. Unterhalter (Eds.), Amartya Sen's capability approach and social justice in education (pp. 25-43). New York, NY: Palgrave Macmillan (2007)

UNICEF Office of Research: Child well-being in rich countries. A comparative overview. Innocenti Report Card 11, Florence (2013)

UNICEF Office of Research: Children of the Recession: The impact of the economic crisis on child well-being in rich countries. Innocenti Report Card 12, UNICEF Office of Research, Florence (2014) 
Wolf, J. \& De-Shalit, A.: Disadvantage. Oxford University Press: New York (2007)

Woodhead, M.: Changing perspectives on early childhood: theory, research and policy. International Journal of Equity and Innovation in Early Childhood, 4(2), 1-43 (2006)

Zakaria, N.F., Sabri, M. F. Review of financial capability studies. International Journal of Humanities and Social Science, 3(9) (2013), 197-203. 